\section{THE HUNTERIAN LECTURES} ON THE

SURGERY OF THE KIDNEY.

Delivered at the Royal College of Surgeons of England, BY HENRY MORRIS, F.R.C.S., Surgeon to the Middlesex Hospital.

LECTURE III.

FISTULA CAUSED BY RENAL CALCULUS ; OBSTRUCTIVE ANURIA DUE TO RENAL CALCULUS; THE TECHNIQUE OF THE EXPLORATION OF THE KIDNEY AND URETER FOR CALCULUS.

Mr. President and Gentlemen,--In the second lecture I endeavoured to show ( 1 ) that the errors and uncertainties in the diagnosis of renal calculus had in many instances been of distinct advantage, because they had led to the exploration of the kidney, and this in turn to the discovery and cure of various morbid conditions other than those due to stone (2) That unsuspected, quiescent, and migratory renal calculi cause very destructive and even fatal consequences, and that we ought to revise our practice with regard to the early treatment of stone in the kidney. (3) That the low mortality of nephrolithotomy (that is, the operation for renal calculus in its early stages); and the high mortality of nephrotomy, and the still higher mortality of nephrectomy (that is, of the operations performed for the advanced disorders due to renal calculus), show the advisability of operating at as early a stage as possible.

In further support of this conclusion. I may point to Table IV, the exploratory operations, and Table V, the operations for movable kidney. There are 42 of the former, and 57 of the latter, without a death due in any way to the operation.

It will be seen in Table IV that three cases are recorded as deaths (Nos, 15, 22, and 25), but a glance at the abstracts shows that the deaths were due entirely to other causes. Two of the patients lived long enough to recover absolutely from the operations, and ought to be counted therefore as recoveries; the third (No. 25) died from obstinate vomiting and hæmatemesis from a gastric ulcer on the second day after the operation, and therefore ought to be excluded.

In Table $\mathrm{V}$ there is not a death from any cause whatever in the whole number (57) of operations for movable kidney.

If $I$ add that in nearly every instance the kidneys operated upon were brought out on to the surface of the loin, and in a very large number of them the convex border of the kidney was incised and sutured, it will be understood that these operations from the point of view of risk are essentially the same as nephrolithotomy.

When the cases in these three tables are added together, excluding the one referred to above, we get the following result :

Table I. -34 operations, 33 recoveries, I death.

$$
\text { "IV. }-42-1=41 \text { operations, } 4 \text { I recoveries. }
$$

". V.- 57 operations, 57 recoveries.

Tötal-132 operations, 131 recoveries, I death.

Thus, out of a total of 132 operations, the essential characters of which are much the same, there were 131 recoveries and 1 death.

At the Middlesex Hospital, where renal operations are freely undertaken by the members of the surgical staff, a good many persons nevertheless die from the effects of renal calculus who are too ill to be operated upon when admitted. During the years 1885 to 1895 inclusive calculi were found in the kidneys in 45 out of 3,33 l post-mortem examinations, and hydronephrosis due to calculus impacted in the ureter was found in 4 others. That is, in $1 \frac{1}{2}$ per cent. of persons dying from all conceivable causes, calculi were found in one or both kidneys or ureters.

Many of these 45 bodies found their way to the post-mortem room entirely because of calculous disease, and in the rest renal calculi contributed more or less to the fatal result. Amongst the 45 cases there were 10 instances of suppuration in one or botn kidneys; I cases of perinephric abscess;
4 cases in which calculi were present in both kidneys, and 4 others in which only one kidney could be said to exist, the other having undergone complete atrophy due to obliterated ureters in 3 of them, and cystic degeneration from obstruction in the fourth.

Besides these 45 cases, there were 63 instances of suppurative nephritis in most of which both kidneys were affected, and in many of them renal calculus had played a conspicuous part.

In considering the harmful effects of renal calculi, it is impossible to leave out of account renal and ureteral fistulæ. It is after nephrotomy for calculous pyonephrosis, especially, that a fistula due to operation is most likely to occur. It is exceptional for a permanent or long-standing fistula to result from nephrolithotomy, or an operation for movable kidney, or a simple exploration. This is rather surprising if we consider the nature of the tissue surrounding the kidney, its proximity to the colon, the fact that there is often an escape of a little urine when the kianey is incised, and that the action of the lower ribs and abdominal muscles in the immediate neighbourhood of the wound is almost incessant, and sometimes violent, as in coughing, retching, and straining at stool.

Fistula is also exceptionally rare after nephrectomy, except when perinephritis or perinephric abscess has previously existed. In cases of nephrectomy for calculous disease perinephritis, however, has usually preceded the operation, but in spite of this a fistula followed in only one out of twelve of my surviving nephrectomies for stone-that is, at the rate of a little more than 8 per cent. - and in that case the fistula was superficial, and probably healed shortly after the patient left the hospital, though I have no certain knowledge that it did so.

Out of my 33 nephrolithotomies which survived a superficial sinus occurred in two (Table I., Nos. I and 9), and a urinary sinus in two (Table I, Nos, 6 and 22). In the two latter very large incisions involving the pelvis of the kidney. had to be made for the extraction of stones of great size.

After nephrotomy for advanced calculous conditions, for example, calculous pyonephrosis, fistulæ, either temporary or permanent, occurred in 37.5 per cent. of the cases operated upon. Though in many of these the fistula subsequently healed, still the fact that even a temporary fistula followed in so large a proportion of cases affords a further argument in favour of early operation for stone in the kidney.

But the fistulæ which occur independently of any operation, which are due in other words to long-retained renal calculi, should appeal even more strongly to surgeons as an argument against delaying operative treatment for stone.

The persistency of these fistulæ, the recurrence of deep suppuration if the external orifice of the fistula is allowed to close, together with the abiding troubles caused by the continued presence of the stone in the kidney or ureter, will sooner or later induce the patient to demand surgical assistance.

Then the patient has to undergo risks and the surgeon to face difficulties which occur only when the perinephric structures are matted and hardened by long standing inflammation or suppuration; and have become so densely adherent to the kidney capsule that it is often no easy matter to find the kidney.

In a stout person with a deep loin it may be quite impossible to distinguish the kidney at all by touch; whilst the resisting nature of the tissues, and the depth of the wound. make it impossible, except through a very extensive incision, and perhaps only after the excision of the last rib, to bring the kidney within sight.

Another and very important fact is that these condensed contracted tissues fill the hilum and surround the whole of the kidney with a fibro-lipomatous mass, which shortens and stiffens the pedicle; and compresses and destroys the elasticity of the renal vessels and of the ureter. The result of this is that the kidney gets tucked close up against the spinal column, and as firmly set in its surroundings as if it were inbedded in plaster of paris. (Specimen shown.) If nephrotomy is done under these conditions the renal artery caunot be controlled when the renal parenchyma is incised and the kidney cavity explored; and thus bleeding is as to he very [1940] 
free. If nephrectomy is performed the risks and difficulties in dealing with the pedicle are enormously increased.

When a fistula is in course of formation the perinephric abscess should be opened as soon as possible, lest the matter should burrow and discharge in some dangerous direction. It is true the abscess will often make for the loin, or groin, and open spontaneously on the surface, if it be not incised; but it should not be suffered to do so.

If on opening a perinephric abscess a calculus presents, or is readily detected on the introduction of the finger into the cavity, it should of course be removed. Several cases of this sort are on record.

It is, however, as a rule, unsafe to search for and explore the kidney when the tissues surrounding it are in an acutely suppurating condition. The safer course is to defer the exploration of the kidney till after the abscess is healed. This necessitates a lengthy convalescence, followed by a fistula; and a second operation, before the cause of the abscess can be lemoved. After this second operation, whether it be nephrotomy or nephrectomy, it is not infrequent for the healing of the wound to be delayed by profuse and prolonged suppuration.

The same drawbacks attend operations for calculous affections of long standing if perinephritis without abscess or fistula has existed. There may be the same matting of the tissues, the same fixation of the kidney, the same inelasticity of the pedicle, the same ingrowth of fibro-kipematous tissue at the hilum, and the same incompressibility of the renal vessels.

If perinephritis has commenced before nephrotomy is performed, neither the extraction of a calculus nor the evacuation of pus from the renal cavity may prevent the spreading of the inflammatory process in the surrounding cellular tissue and the formation of a fistula at a long distance from the kidney. A case was narrated in which it was necessary to excise portions of the 9th, roth, and I ith ribs (the inth had heen removed at a previous operation) before the fistula would heal.

In a collection which I have made of unselected cases of fivcula dur to renal calculi, some of the fistulæ followed the bursting of pyonephrotic kidneys; and others were the result of perinephritic suppuration and the bursting of the perirenal abscess. Some opened spontaneous'y into the lung others into the stomach, or duodenum, or colon; one int the colon and the lung, and as both of these organs communi cated with the renal pelvis, it thus happened that the lung communicated with the colon. ${ }^{1}$ Of those which opened on the external surface, one did so below the trochanter, on between the 8th and 9 th ribs, one or two in the groin, but the majority in the loin.

When a perinephric abscess burrows beneath the ribs and points posteriorly in an intercostal space, the course taken by the pus is through the costo-diaphragmatic hiatus (shown in diagrams from Testut's Anatomy). This hiatus, formed by the absence of the muscular fibres of the diaphragm, exists on both sides of the trunk, and gives facility for the ascent of pus between the liver and peritoneum, or spleen and peri toneum in front, and the ribs and intercostal muscles be hind. Judging from the cases I have seen, the lung is pushed upwards, and the pleura upwards and forwards. Thus the resulting fistula can be dealt with without opening either pleural or peritoneal cavity.

A fistula of calculous origin may either be in communication with the kidney or ureter; or may be limited to the perinephric tissue. In one case (described in my book on the Surgery of the Kidney) the fistulous track went straight through from the surface to the kidney, there being no burrowing or abscess space in the perinephric tissue (specimen shown).

After an operation in which the kidney has been incised, a fistula may end in a smooth-lined space, containing more or less pus, and surrounding one or other pole of the kid but without any communication whatever with the kidney or ureter. A fistula may have a communication with the renal cavity or ureter without there being any escape of urine through it; this can in some cases be demonstrated by the injection into the fistula of an aqueous solution of fuchsin. If the communication is free and direct, evidence of the coloured solution having reached the bladder will be obtain- able in a few minutes, as in Nos. I and 2, Table VIII; if the communication is small and indirect, an hour or two may be required before proof is obtained.

The closure of the fistula by surgical treatment is tedious, and sometimes impossible; and in some cases, after having been successfully treated and remaining closed for mauy months or a year or two, it will reopen.

Those which do not communicate with the kidney or ureter should be treated on the ordinary principles applicable to all fistulæ; those which do so communicate must be dealt with differently in different cases. If there is a calculus in the kidney it must be removed; if the kidney is quite disorganised, nephrectomy is requisite; if the kidney is not disorganised, the fistulous tract should be cut out and the cut surfaces united by sutures. This I did in the case of No. 14, Table VII, with success. When no stone is found in the kidney, the ureter will probably be the seat of some kind of obstruction. There may be an impacted calculus; a stricture following inflammation or ulceration caused by a calculus which has escaped; or a stricture as the result of contraction after periureteritis; or the duct may be distended in one part and contracted in another by suppurative ureteritis. In most cases a renal or ureteral fistula of calculous origin will, I believe, close permanently after nephrectomy, even if a stone be left impacted in the ureter, or the ureter be in a state of suppuration at the time of the operation. But should it not do so, it may be necessary, as in the case of fistula kept up by tuberculous ureteritis, to perform partial or complete ureterectomy.

A urinary fistula, due to obstruction in the ureter, may in time cease to discharge urine, owing to complete atrophy of the kidney. The length of time required for this to be accomplished depends on the degree of obstruction which the fistula on the one hand, and the ureteral block on the other hand, offer to the escape of urine. The more complete the obstruction, the more rapid the atrophy, and vice versa. In a case of my own the process took seven years. ${ }^{2}$ Even after a fistula ceases to be urinous, it may persist as a suppurating sinus.

Two objections to early operations for renal calculus are : (1) that calculi will be missed if sought for very early, because of their small size; (2) that very small calculi, if they once enter the ureter, pass through the urinary passages without risk to life. Both these objections are unsound, and lead to dangerous delay.

In the lists of my operstions for calculus, it will be found that stones of all sizes, from two grains to ten ounces, have been removed by nephrolithotomy or nephrotomy ; and I do not think one, however' small, will be missed becauee of its small size with the present mode of exploring the kidney and ureter.

The second objection is even more invalid than the first; for there is anule proof that a very minute calculus may provoke the coanplete destruction of the kidney, or become the immediate cunse of death from suppression of urine.

The accompanying figure (Fig. 16) of a pyonephrotic kidney shows the closure of the ureter at its renal end by the impaction of two ting stones, and the entire destruction of the kidney in consequence. (Vide No. 14, Table III.)

In some of my cises the most continuous and profuse hrmaturia has been caused by small stones. But-worse than hæmaturia or the destruction of a kidney-calculi weighing less than two grains have caused death

Sir William $R$ sberts, in his admirable chapter on Obstructive Suppression of Urine, records a case where three little oxalate of lime calculi about the size of hemp seeds, and weighing altogether one grain and a-half, were found in the lower part of une ureter. One of these was tightly impacted in the terminal part of the ureter, where it passed through the coats of the bladder; this was the cause of the obstruction which resulted in the death of the patient from anuria.

In another case he tells how the secretion of urine was suddenly and permanently arrested by a uric acid calculus about the size and shape of a hemp seed, which weighed only one grain and a-third, and which, becoming impacted in the ureter just above its entrance into the bladder, destroyed the patient in less than ten days.

In a third case a similar course of events was brought about 
byia round uric acid stone the size of a small pea, which weighed only one grain and a-half.

In all these cases the opposite kidney had previously been destroyed or obstructed, and the little calculi caused death from anuria by obstructing the ureter of the hypertrophied and only kidney which was acting.

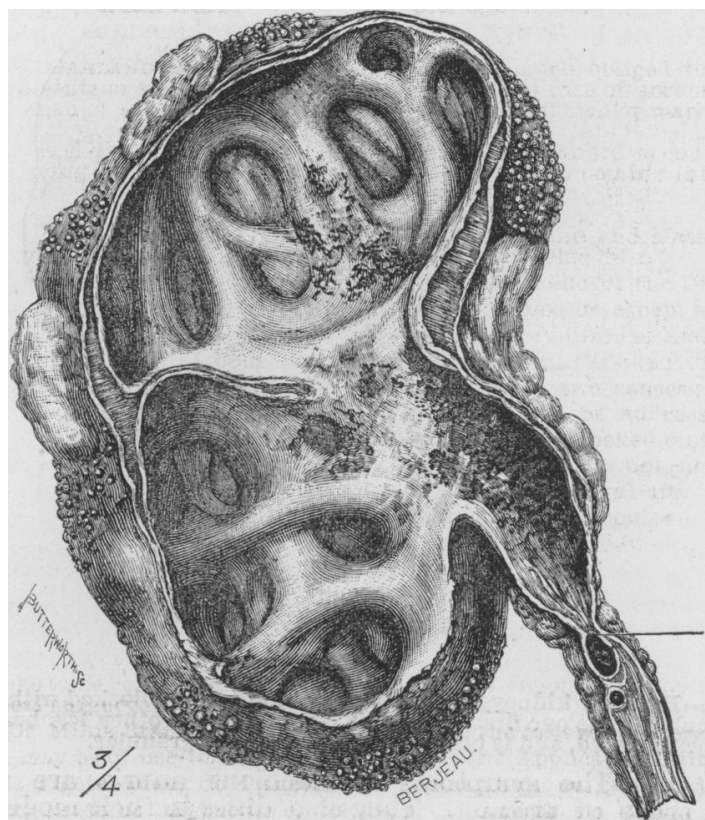

Fig. 16.-Kidney (showing minute calculi blocking ureter) removed by operation. Recovery. Author's case.

\section{Calculous andria.}

Calculous anuria is the gravest and most fatal of the many serious complications of renal lithiasis. Special attention was given to it in 1872 by Sir William Roberts in the second edition of his classical work on Urinary and Renal Diseases, v. 23, $t$ t seq.; and in 188, an exhaustive thesis on anuria by Pierre Merklen was published in Paris; but neither in this nor in Roberts's book is the subject of the surgical treatment of calculous anuria considered.

In his 1885 edition, Sir William Roberts, it is true, s87s in a footnote: "Lately it has been recommended to open the areter or pelvis of the kidney above the obstruction, and so establish a permanent urinary fistula." Bnt, though antispasmodics and a variety of mechanical means are recommended, and diuretics are rightly condemned, still surgical aid was not seriously discussed by either Roberts or Merklen.

Even at the present time the principle of the operative treatment of calculous suppression of urine is either imperfectly known or improperly appreciated by the profession in this country, because operations are certainly neither sufficiently early nor sufficiently often performed; and, worse still, patients are sometimes told by physicians that no surgeon in his senses would dream of an operation in their condition.

Since 1885 two or three excellent theses on this subject have appeared in France by Legueu, Donnadieu, Glantenay, and Vailhen; and in England, though nothing bearing generally on the surgical treatment of calculous anuria has been published, some brilliantly successful operations by the lumbar route have been reported, notably by Clement Lucas, Ralfe and Godlee, and Kirkham, who were amongst the first English surgeons to operate in these cases.

Etiology.-Calculous anuria occurs when the ureter or renal pelvis of one kidney is occluded by a calculus, the other kidney being absent, or atrophied, or diseased. It often affects persons in robust health, and may be sudden and complete in its onset. It is then due to the cessation of function of a kidney which has undergone compensa'ory hypertrophy, and which ap to the moment of obstruction had been secreting the whole or the chief part of the urine. Occlusion of one ureter never gives rise to fatal anuria if the opposite kidney and ureter are normal.

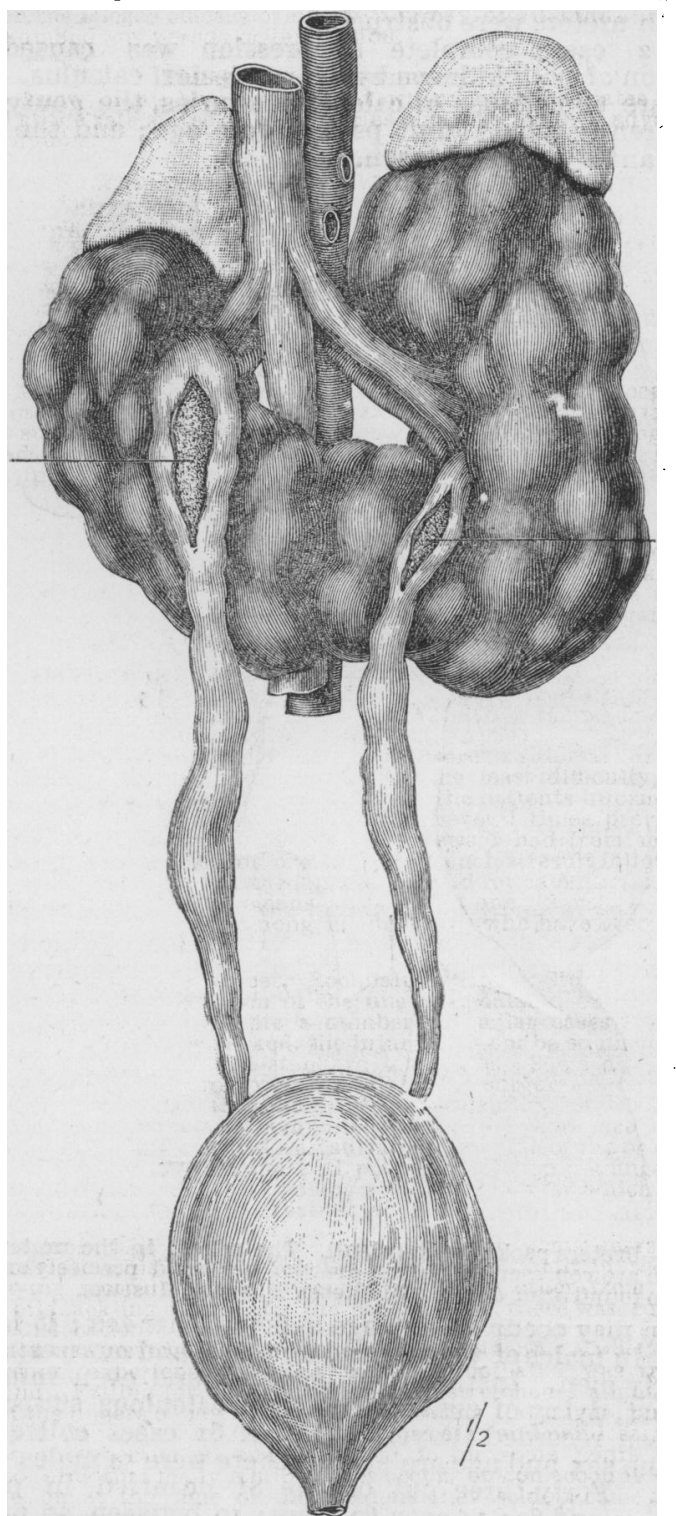

Fig. 17.-Horseshoe kidney with a calculus in each ureter. Post mortem specimen. Middlesex Hospital.

In the most typical pathological condition of calculong anuria there is occlusion of both ureters by calculi (see Figs. 17, 18, and 19). The following description and statements are based on two sets of cases collected by the authornamely, 48 cases not operated upon and 49 operated upon. The last table (XI) consists of the collected cases operated upon.

In 55 cases the situations of the calculi were noted to be as follows:

I. In the renal pelvis and blocking the upper orifice of the ureter, 7 cases. In 4 of these both ureters were blocked, one stone being in each upper ureteral orifice.

2. In thi upper end of the ureter, 30 cases. Both ureter 4 were blocked in 5 of these cases. In 3 there was anoth stone impacted lower down -2 in the midpart and I near the bladder.

3. In the middle portion of the ureter in 7 cases. In 
I case both ureters were blocked, and in 2 others there was a second blockage by calculus higher up.

4. In the lower end of the ureter in 10 cases. In I of these there was an impacted stone also higher up, in 3 of them both ureters were obstructed.

5. In 2 cases complete suppression was caused by obstruction of both kidneys by a large vesical calculus.

There are two classes of calculous anurics, the gouty, fat, and apparently robust adult past middle age; and the thin, nervous, and dyspeptic person.

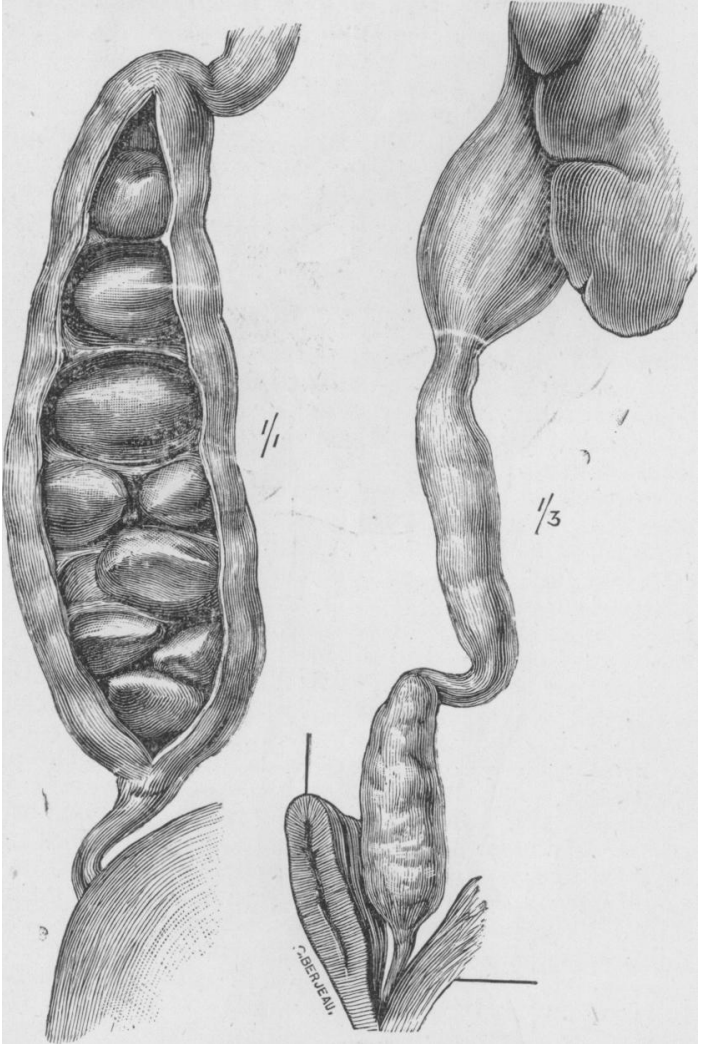

Fig. 18.- Ureters packed with calculi. The calculi in the ureter laid open are represented in the drawing arranged precisely as they were found after death. Middlesex Hospital Museum.

Anuria may occur at any age and in either sex ; it is more frequent in males of 35 years and upwards, and more especially in elderly men. Instances of children, and even infants at the breast, dying of convulsions from calculous suppression have been recorded (Rayer). Out of 81 cases collected, in which the sex and age are stated, there were 54 males and 27 females. Forty-three out of the 8i ocsurred in persons between 40 and $60 ; 15$ over 60 years; 19 between 20 and 40 ; one before 10 years of age: and 3 between 10 and 20. The youngest was aged 6 , and the eldest 80 .

Much importance ought to be attached to the antecedent history of patients who become the subjects of suppression of urine from ureteral obstruction. Commonly they have had several previous attacks of renal colic or of lumbar pains, followed by the discharge of gravel or small stones, months, or even years, before the attack in which the anuria begins. But cases have occurred of sudden suppression of urine from obstruction by calculus without a previous attack of any kind. In such cases both kidneys have been gimultaneously obstructed, or one kidney has been destroyed by disease of another kind, or has been congenitally absent or abnormal.

Calculous anuria is often determined, or immediately in luced, by fatigue: a drive or some other shaking movem int such as jumping from an omnibus, violent coughing, $r$ widly running from the garden to the house on hearing a lo d peal of thunder, are some of the causes in my own cases which started the descent of the calculi from the kidney into the ureter.

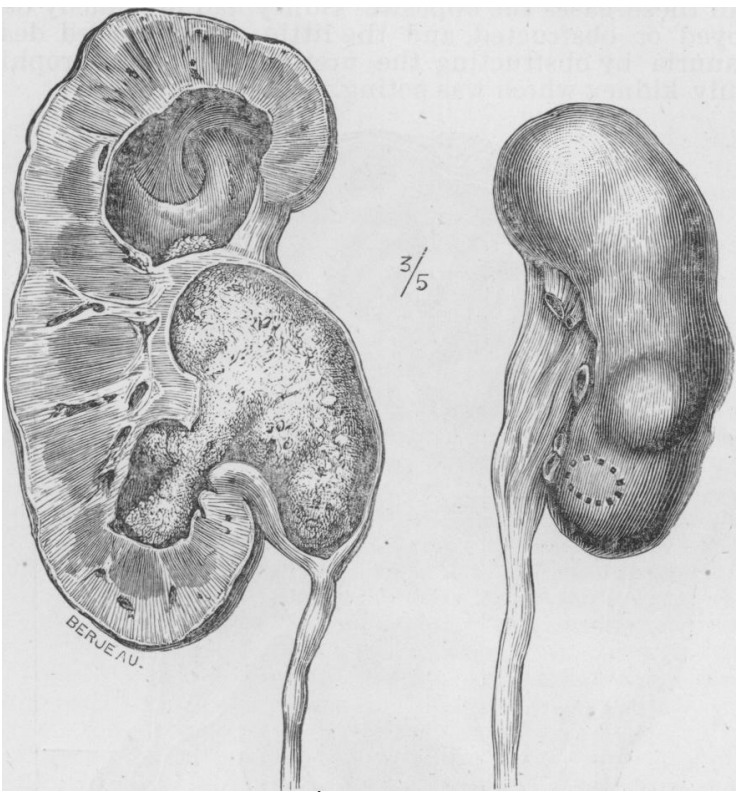

Fig. 19.-The two kidneys of the same person, each blocked with a calculus. The one first affected is atrophied, the other has been hypertrophied, and is becoming sacculated and granular.

Symptoms.-The symptoms of calculous anuria are not simply those of uræmia. They also differ in their mode of onset, and in their character, from some other forms of obstructive anuria, such as anuria from cancer of the uterus; from the pressure of abdominal tumours; and from torsion, curves, or stricture of the ureter; as well as from toxic reflex, and hysterical and other non-obstructive forms of anuria.

When the uræmic symptoms set in they exhibit marked differences from the uræmia of lardaceous disease, of Bright's disease, and of other forms of nephritis.

Though in rare instances the onset is insidious, acute pain is almost invariably experienced in the region of the kidney involved last, at the outset of the suppression. The pain so started may continue throughout the anuria, but more commonly it is temporary, lasting only a day or two, or less, and then subsiding. Less frequently the first symptom is a dull and continuous aching in the lumbar region, with or without pains radiating along the course of the ureter. In very exceptional cases the anuria has come on without pain on either side, and without the history of previous attacks of renal colic; or the patient has quiteforgotten on which side the previous attacks of colic were. These, fortunately rare, are the cases in which the surgeon may have no guide as to which kidney to operate upon.

With the pain there may be troubles of micturition, such as continual desire to pass water, though not a drop of urine may be in the bladder; or the urine is passed with difficulty, and sometimes only in drops or teaspoonfuls. Or, on the contrary, there may be polyuria, the urine being pale and of low density, and showing evidence of imperfect renal function. In other cases the anuria is intermittent, ceasing, after some hours or a few days, to reappear, and become definitely established.

Calculous anuria may be complete or incomplete. In the complete suppression the bladder is quite empty, or, if not, contains but a few teaspoonfuls of bloody urine. In the incomplete form the anuria is intermittent, but progressive, and interrupted by discharges of urine, insufficient to satisfy the requirements of the system, but sufficient to retard the fatal termination of the disease. When the working kidney is hydronephrotic the uræmic condition may be deferred for a longer time than otherwise, even if there are no polyuric intermissions. 
Calculous anuria, once established, may last many days without causing any symptoms of uræmia. This is perhaps its most striking feature, which it shares with other forms of obstructive anuria, and with anuria which follows ligation of the ureters, as distinct from the non-obtructive forms. Even when the suppression is complete, seven, eight, or ten days may elapse before the symptoms of uræmia appear, and sometimes death occurs without any of the characteristic symptoms of uræmic poisoning arising at all. When the uræmic phenomena supervene after a longer or shorter time, death follows rapidly, or, at any rate, within a day or two. Thus it happens that authors have come to distinguish two cases in the progress of calculous anuria ; namely, (1) the silent or tolerant period; and (2) the uræmic period. But it is important to remember that death may occur as just mentioned without the supervention of the second or uræmic period occurring.

In the period of tolerance the patient, though he may not pass a single drop of urine for several days, may yet walk about, eat, and do mental work in all the appearance of good health. This fact must never be forgotten if a serious mistake in diagnosis and prognosis is to be avoided; it is, however, all the more likely to escape notice, because it is so opposed to the course of suppression due to non-obstructive causes.

In certain cases, as in those recorded by Paget and Weber, polyuria occurs, and retards the appearance of uræmic phenomena as well as the fatal termination, which, however, at length arrives just the same.

In Paget's case polyuria occurred on the thirteenth day, and death was deferred till the twenty-second day. In Weber's case a succession of remisslons of polyuria took place, and the fatal result was not reached till the thirtieth day from the onset of the anuria.

In one of Roberts's cases the patient lived fifteen days. Tenneson ${ }^{3}$ reported a fatal case in which the suppression lasted fifteen days. Dr. Ernst Bischoff reported the case of a man aged 58, who for fourteen years had suffered from gout and lithiasis; he had had repeated temporary suppression for several days together; then twenty-three days of anuria, with two very slight intermissions on the fifth and fourteenth days, attended by cdema, fever, and aphthous stomatitis and very high temperature. The post-mortem examination showed a very small left kidney, but in a state tending towards compensatory hypertrophy, with calculi in both ureters and in the left renal pelvis.

Symptoms when Hydronephrosis is Associated with Anuria.When the working kidney is hydronephrotic, patients with calculous anuria may escape uræmic accidents for a much longer time than others, without having polyuric remissions.

Thus in a fatal case of a man aged 64 recorded by Rayer, ${ }^{4}$ with an enormous hydronephosis, the anuria lasted twentyfive days, with only a slight remission on the tenth day. James Russell published a case of anuria lasting twenty days, which terminated by the discharge of 10 litres of urine in twenty-four hours; but a year later the patient died, and at the post-mortem examination there was discovered double hydronephrosis with calculi in the pelvis of each kidney.

Roberts cites a case of calculous anuria of ten days' duration, with an increasing tumour in the left iliac fossa; recovery followed a veritable urinary crisis coincident with the disappearance of the tumour.

But whilst hydronephrosis is exceptional in calculous anuria, and such marked polyurie remissions are uncommon, it is, on the other hand, much more frequent for the secretion of urine to cease definitely shortly after the establishment of the obstruction.

Hydronephrosis occurs only when anuria is repeated on many occasions, for a brief period only, or in an incomplete manner; that is to say, when the obstruction is intermittent, or imperfect and progressive.

Uramic Stage. - At a variable period the second or uræmic stage sets in. When the anuria is complete this period arrives mostly about the seventh or eighth day.

The symptoms of the uræmic stage may be summarised ander three groups: $(a)$ the circulatory; $(b)$ those connected with elimination; and $(c)$ those of poisoning.

(a) The pulse is slow and full, and later becomes irregular. Epistaxis in one case was very abundant; œdema about the mallenli and even a true anasarca - the result of venous stasis not of albuminuria-have been observed in a few cases by Sir William Roberts, Russell, Ernst Bischoff, Tenneson, and Merklen. The temperature is low, as in all forms of uræmia, namely, from $97^{\circ}$ to $97.6^{\circ}$.

(b) Profuse perspirations may occur, but if so, are suppressed in the last day or two of life. The older writers state that the sweat has the odour of urine; but modern writers following Roberts dispute this. Roberts, indeed, goes further, for he says (4th edition, p. 34) "there is never any ammoniacal or urinous odour from the breath or skin, nor from the body after death." In one of my cases, in which there had been suppression for nine days, twelve hours before death the patient's "extremities became cold and clammy, her face swollen, and the breath strongly ammoniacal. The body began to be offensive a few hours after death."

In the absence of sweats, cases of itching of the skin, pruriginous eruptions, and erysipelatous swelling of the whole body are quoted by Rayer; profuse salivation is noted by Weber; blood-stained expectoration by Foissac and Paget.

But more important than the foregoing symptoms is vomiting. This is copious, and due to gastric irritability rather than to supplementary elimination. It is a symptom of bad omen, which precedes and accompanies the uræmic nervous phenomena. Obstinateconstipation and meteorism are common intestinal symptoms. Meteorism may be particularly troublesome. Sometimes there is a veritable intestinal paralysis. Diarrhca, a common and marked symptom in some cases of uræmia from lardaceous disease, is very exceptional in calculous anuria.

(c) Contraction of the pupils and muscular tremors are the two most marked symptoms of the poisoning stage. The intelligence may be perfect to the last moment, but more often it becomes, after a while, impaired, the patient being in a state of semi-sleep, from which, however, he is easily aroused. Occasionally delirium or hallucinations occur. Incessant restlessness and an overpowering feeling of heaviness and general fatigue are, when they exist, the immediate precursors of death. The limbs, instead of being affected by muscular twitchings and agitations, may be benumbed or as if paralysed. The temperature falls lower with the progress of the disease. The respiration becomes slow and sighing and irregular, and the patient dies from paralysis or powerlessness of his respiratory muscles. Or the patient may die of heart failure, without a convulsion, without coma; occasionally death is caused by coma, or a convulsive crisis ; and sometimes by an attack of suffocation, two or three days after the commencement of the uræmia.

Prognosis. - The usual termination of calculous anuria when left to itself is death about the tenth or eleventh day. If, however, the suppression is interrupted by intermittent polyuria, whether hydronephrosis exists or not, life may be prolonged by many days. Spontaneous cure sometimes occurs. Legueu states that out of 56 cases of calculous anuria, which neither followed nor were treated by operations, recovery took place in 16 , that is, in 28.5 per cent. In one the secretion recommenced on the third day; in ro between the fifth and tenth days; and in the rest on the thirteenth, fourteenth, fifteenth, twentieth, and in two instances on even a still later day. Of the 40 deaths 23 occurred between the fifth and fifteenth days, I on the fourth day, and the rest on and after the sixteenth day.

Of the 48 cases in my table of cases not operated.upon, 38 died and ro recovered; of the 49 cases operated upon, 24 died and 25 recovered. Thus there is a percentage of recoveries in cases operated upon of 51 , as against 20.8 in cases not operated upon. These figures speak loudly in favour of peration for calculous anuria.

Merklen says that while it is uncertain up to what date we may hope for spontaneous recovery, the chances of recovery diminish with the prolongation of the anuria. According to Sir William Roberts, the fatal termination is at hand when contraction of the pupils and convulsive tremors of the limbs occur. Recovery, he thinks, may be hoped for as long as these phenomena have not been observed.

The pathological anatomy of calculous anuria may be summed up in the statement that the ureter or renal pelvis of one side has recently become occluded, while the kidney of the other side is either congenitally absent or functionally suppressed, or structurally destroyed by calculus, or some other 
form of renal disease. Rarely does simultaneous obstruction of both ureters by calculi occur, although this has been known to happen.

Diagnosis. - The occurrence of former attacks of renal colic in a gouty person, followed by the sudden onset of pain on one side, and this accompanied or immediately followed by anuria, points at once to obstruction of a calculous nature. The diagnosis will be further strengthened if a swelling, or dis tinct tenderness on pressure, is present in the renal region, or in the course of the ureter, of the side recently become the seat of pain.

But in some cases there is not a distinct history of previous attacks of renal colic, and yet one kidney may have become silently but entirely obstructed, or destroyed by calculi, as shown in Lecture II. In other cases there have been previous attacks of renal colic or pain, but the patient has forgotten on which side the pain was felt.

If under these circumstances anuria sets in it may be difficult, or impossible, to diagnose on which side the recent obstruction exists. The surgeon thus in doubt must seek information by the examination of the patient in the following manner

I. The course of the ureter should be palpated, if possiole, through the abdominal parietes. This is often an impossibility owing to the stoutness of the patient. The ureter in which a calculus is impacted is likely to be inflamed and painful, as well as tender; even when a calculus has passed along the ureter it is likely to be followed by pain lasting several days after its escape.

2. Rectal and vaginal examination should be made. In the male digital examination per rectum has led to the discovery of a calculus im pacted in the lower part of the ureter, as in Rawdon's and Ceci's cases ; in the female the same discovery has been made by vaginal examination by Emmet and by myself, and I have also detected the presence of a stone by vesical examination after dilating the female urethra.

3. Catherisation of the ureters, though easy of application in the female, does not afford satisfactory assistance in these cases, whether done across the bladder through the dilated ureter, or by vaginal cystotomy as practised by Bozemann and Emmet, or by the aid of suprapubic cystotomy. The cystoscope in the cases of anuria is quite unnecessary, and can give no information which is not more fully ascertained by rectal or vaginal examination and a sound in the bladder.

If there bo a calculus in the terminal part of the ureter it will almost certainly, if of any size, be detected by either rectal or vaginal examination, and can be extracted by one of the operations to be mentioned later on; but if by these modes of exzmination nothing is detected in the inferior extremity of the ureter, we ought without delay to explore one or both of the kidneys through the loin, and to select first the side on which pain, or tenderness or swelling or a hard contracted condition of the abdominal walls exists, or has recently existed. Through such an incision the kidney and adjacent part of the ureter can be seen and felt, and the rest of the ureter catheterised, and if a stone be found it will be possible to remove it, and if no stone be found then by establishing a ren 1 fistula relief will be given to the congested state of the kidney, and a condition will thereby be brought about favourable to the resumption of the secretion of the urine.

Calculous ar uria and uræmia have to be diagnosed from non-obstructive forms of anuria, and from other forms of obstructive diseave.

From Polycystic Disease.-A case of anuria from double polycystic disease, in which the symptoms and history were those of calculous obstruction, has lately been under my care. The patient, a rather stout but well-made, muscular man, aged 50 , first had pain in his right loin in 1884 . Subsequently he frequently passed gravel, and in 1894. after attacks of pain in the right kidney, a small stone. He has been in very indifferent health since then. suffering pain in the right loin. On Wednesday, March 16th, he had another attack of pain like the former ones. but in the left side as well as the right, and passed very little urine after then. Both his kidneys were cut down upon, first the left, then, two days later, the right. Both kidneys were found in the same state. Several cysts were opened in each, and the lessened tension resulting therefore gave him some relief. He died on March 24th, on the ninth day of the attack, and after five days of complete suppression. Muscular twitchings, meteorism, sleeplessness, restlesssness, a small, rapid pulse, pallor of face, blueness, and coldness of extremities, and at last subnormal temperature and dyspnœa were the chief symptoms. The kidneys and liver are before you; each of these organs is in a state of cystic degeneration. There was no stone or other gross obstruction present throughout the urinary organs.

From Uterine Cancer and Pelvic Tumours.-Cancer of the uterus is after calculus the most frequent cause of obstructive anuria. I have seen many cases of anuria. from uterine cancer in the cancer wards of the Middlesex Hospital; but I do not remember ever to have seen uræmia from this cause arise before any of the ordinary symptoms of carcinoma of the uterus have declared themselves. Such cases, however, have been recorded, and have given rise to difficulty in diagnosis, as the suddenness of the attack suggested calculous anuria. Avan reported a fatal case of uræmia attended by eclampsia and prolonged coma in a woman who had never complained of any of the symptoms of uterine cancer, and who was suddenly seized with eclampsia in the street and died. Cancer of the uterus was found on post-mortem examination to have caused double hydronephrosis by pressure on the ureters.

Complete and prolonged suppression of urine at an early period of the cancer, or in uterine cancer which has been latent up to the onset of the anuria, is also recorded. Merklen. quotes cases of total suppression for seventeen and twentyone days due to uterine carcinoma, which had not previously caused any of the classical symptoms of the disease. Roberts also cites a case of the same kind, in which anuria lasted fifteen days, and presented the clinical symptoms and followed the course of calculous anuria. Such cases are very prone to be mistaken for anuria from impacted calculus.

Primary cancer of the bladder may obstruct the ureters, like uterine cancer when it has invaded the trigone. Roberts records a case in which the symptoms were those of calculous anuria; but at the post-mortem examination scirrhous carcinoma at the base of the bladder was found, involving the prostate gland, and both ureters passed for the length of an inch through the growth. Double hydronephrosis-old on one side, recent on the other-was the result.

Suppression has been known to occur suddenly, and to be followed by uræmia, vomiting, and fever, as the result of secondary carcinoma in the renal pelves and ureters. Voluminous tumours of the uterus or its appendages may obliterate the ureters and give rise to suppression.

Many cases after operations for myoma of the uterus succumb to anuria with dilatation of the ureters and renal pelves.

The diagnosis between calculous anuria and cases of anuria from uterine cancer, and the other causes of ureteral obstruc tion, will be assisted by digital examination of the vagina and rectum, and by palpation of the abdomen.

From Traumatic Anuria.-Calculous anuria will be diagnosed from traumatic anuria, in which the vessels of both kidneys are thrombosed, by the symptoms following an injury; and from the anuria following catheterisation and other operations on the lower urinary passages, by the absence of the general malaise at the onset, and of the rigors, high temperature, and intense prostration which accompany urinary fever. After extensive thrombosis of the vessels (arteries or veins) of both kidneys polyuria has been observed, as in a case recorded by Moxon in vol. xiv of the Guy's Hospital Reports.

Treatment.-The treatment of anuria, up to fifteen years ago, was entirely medical. Death was the common result. No wonder; for what else could be expected from purgatives and diuretics, from diaphoretics and antispasmodics, from baths, forced exercise, and massage? Drugs, such as digitalis and pilocarpin, and others, which induce the elimination of a considerable quantity of water from the system, remove only a small quantity of urea with the water, and thus leave the blood proportionately more highly charged with urea. For this reason, such supposed remedies ought to be ordered with extreme precaution in obstructive anuria.

The surgical treatment of calculous anuria is a question of the day, and one of the greatest importance. 
Nephrotomy should be performed in the gravest cases to prevent death from uræmia; in the slighter and intermittent cases, to extract a stone which may at any time produce complete persistent anuria.

Opinions have hitherto differed as to the precise time when the surgeon should interfere. To be successful it is certain that the operation should be done early and before the uræmic stage is reached. But since this stage is generally delayed till after the sixth day, some authors have advocated the fifth or sixth day as the period of surgical operation.

My opinion is that an operation ought to be performed as soon as the anuria is established and the diagnosis is satisfactorily made.

The operation is serious only on account of the condition for which it is performed, namely (1) the urinary suppression produced by the obstruction, (2) the poisoned condition of the blood produced by the suppression, and (3) the structural changes in the kidney, the consequences of the obstruction. We should operate on the eide last affected when the indica. tion on this point is clear. It is not the kidney which has longest suffered, or which has yielded most calculi, which ought to be incised. The contrary ought to be the rule, because the more the kidney is affected the more extreme its degeneration, the less the secretion which it will yield, and, consequently. the less the benefit from nephrotomy.

In the absence of exact history, drawn from the patient himself, it is necessary to try and ascertain by careful examination of the abdomen which kidney to explore. When there is no enlargement of the kidney, and no pain or tenderness, there may yet be a considerable degree of hardening from contraction of the abdominal muscles over the part of the kidney which is last involved.

In most cases it will be best to explore the kidney first, but in certain exceptional instances, as when the stone can be felt per rectum or per vaginam, or evidence clearly points to the side and precise spot at which it is impacted, ureterotomy should be done. For this nothing less than actually feeling the stone through the abdominal parietes (a most unlikely thing in persons suffering from calculous anuria) ought to satisfy. The localisation of stone, as to whether it be in the kidney or ureter, is very uncertain; most frequently, when impacted in the ureter, the symptoms it causes are referred to the corresponding kidney; but occasionally the reverse obtains, and a stone in the renal pelvis gives rise to fixed abiding pain and acute tenderness at one particular spot in thr course of the ureter.

The nature of the operation performed in the 49 collected cases was as follows

1. Operation stated as nephrotomy (in a few cases as exploration of kidney) in 36 cases. In 1 of them the operation was performed by the thermo-cautery.

2. Incision of the renal pelvis, 5 cases; I was done by thermo-cautery.

3. Incision of the ureter, 7 cases; I was performed through the rectum: in I additional case an attempt was made to remove an obstruction from the lower end of the ureter by means of the finger in the bladder.

\section{REFERENCES.}

1 Specimen in St. Bartholomew's Hospital, 2 Injuries of the Ureter, Edinburgh Medical Journal, January, 1898. 3 Gaz. Hebdom., 1879. 4 Mal, des Reins, T. ili, p. 490.

\section{(To be continued.)}

a Medical Politician.-Sir Charles Nicholson, Bart., M.D., D.C.L , LL.D., who lately entered on his 9oth year, is one of the grand old men of Australia. He took the degree of M.D. at Edinburgh in 1833 ; in 1834 he emigrated to Australia and established himself in practice in Sydney, then the only town of any size in the great southern continent. In'eresting himself in public aff $₫$ irs, he was returned in 1843 to the first rudimentary Australian Parliament, where he had as a colleague Mr. Lowe (afterwards Lord Sherbrooke). Sir Charles presided as Speaker over three of the early Australian Parliaments, and he was also largely instrumental in founding the University of Sydney, of which he was elected first Chancellor. On the separation of Queensland from New South Wales, he became the first President of the Queensland Legislative Council. He has for some years past been living in England.

\section{THE PATHOLOGY AND TREATMENT OF GENU VALGUM,}

By CHARLES A. MORTON, F.R.C.S.,

Professor of Surgery in University College, Bristol ; Surgeon to the Bristol General Hospital.

IT was not my intention to publish the results of my investigations into the pathology of genu valgum at the present time, but the publication of a skiagraph of the bones in this deformity in the British Medical. Tournal of December 4 th 1897, has induced me to do so. Mr. Tyack, Lecturer on Physics in University College, Bristol, has now taken for me skiagraphs of six cases of genu valgum, and they all show that there is no rickety curve in the lower end of femur and no elongation of the internal condyle, but that the deformity is due to curvature outwards of the tibia just below the head, associated with a corresponding curve in the shaft of the fibula which is most marked about the middle of that bone, so that the tibia and fibula at that level are much nearer together than in the normal limb. That this is the essential change in the bones in genu valgum, and not an exceptional one, is shown by the fact that it is present in every one of the six consecutive skiagraphs. The generally received view that the deformity is due to a change in the lower end of the femur is thus shown to be erroneous, at any rate with regard. to young children.

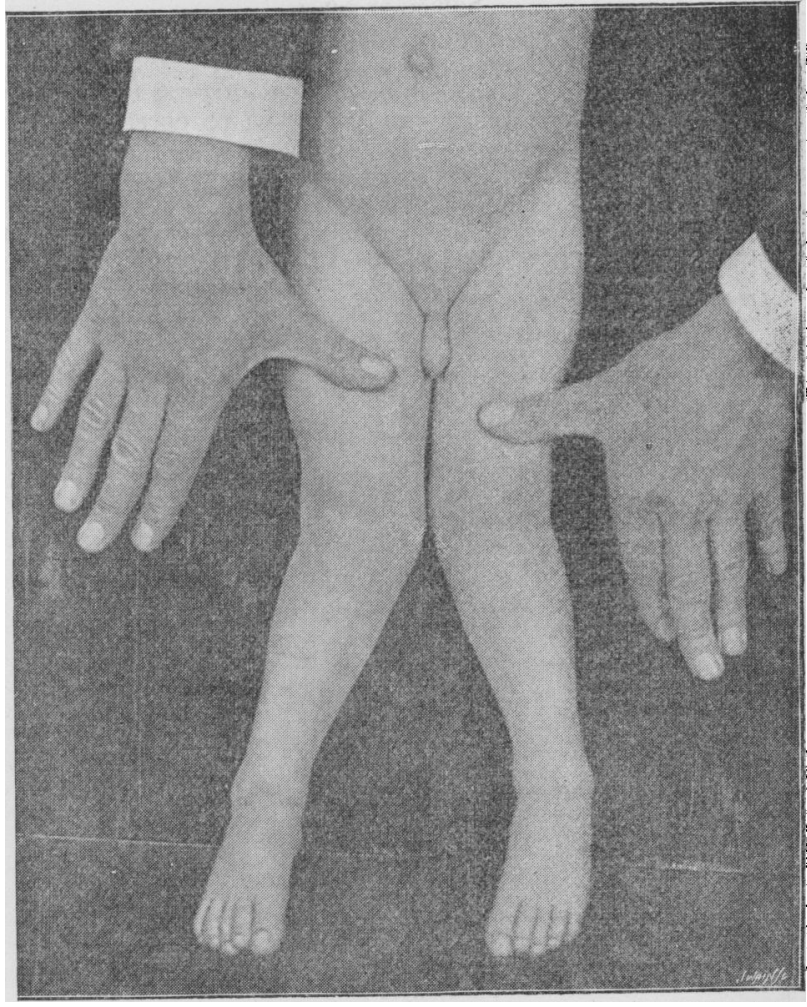

Photograph No. $x$.

Skiagraph No. I is the first taken and the one I wrote to the British MeDiCal Journal about on May 29th, 1897 . It was taken to show the supposed changes in the lower end of the femur, and hence but little of the leg bones is seen, but there is enough visible to show where the deformity was situated. Photograph No. $I$ is of the same case. Skiagraph No, 2 is al $\circ 0$ from the same case, taken after Macewen's osteotomy on both sides, and as more of the leg bones is seen it is really a better one of the deformity. Photograph No. 2 is from the same case after operation, and shows that although the curvature in the leg bones remains unaltered, the limbs are quite strajght. Rectification of deformity of the limbs has been obtained by the production of slight 